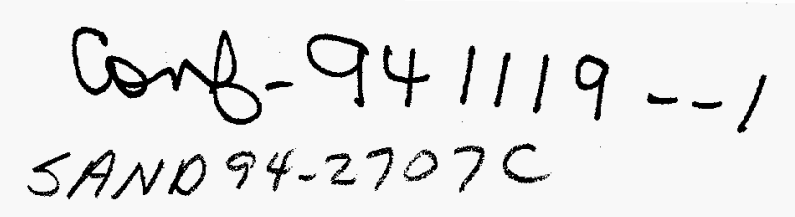

\title{
APPLICATION OF HTS TECHNOLOGY TO CARDIAC DYSRHYTHMIA DETECTION
}

\author{
Annette L. Sobel, M.D., M.S. (1), and William F. Avrin, Ph.D. (2) \\ (1) Sandia National Laboratories, P.O. Box 5800, Albuquerque, New Mexico 87185 \\ (2) Quantum Magnetics, Inc., 11578 Sorrento Valley Road, San Diego, CA 92121
}

Abstract- This paper discusses the conceptual design considerations and challenges for development of a contactless, mobile, single channel biomagnetic sensor system based on High-Temperature Superconductor (HTS) Superconducting Quantum Interference Devices (SQUIDs) and employing the Three-SQUID Gradiometer (TSG) concept. Operating in magnetically unshielded environments, as areencountered in many medical scenarios, this instrument class would monitor cardiac electrical activity with minimal patient preparation and intrusiveness, and would notionally be coupled with a clinically adaptive human-system interface (HSI).

Key-words: Biomagnetism, HTS SQUID, TSG, Dysrhythmia

\section{Introduction}

Although the main emphasis in biomagnetism has been on complex multichannel systems, simple portable instruments may be useful in the setting where "fingerprinting" of the ventricular signal may be sufficient in the classification of ventricular ectopy and subsequent triage. The application of biomagnetic multichannel systems to source detection of cardiac dysrhythmias has been previously described $[1,2]$.

The HTS platform is chosen due to the potential for elimination of much of the difficulty and expense of cryogenics for SQUID biomagnetism. HTS SQUIDs can be cooled with liquid nitrogen, which is much less expensive and easier to transport than liquid helium. In addition, the requisite temperatures may be achieved using inexpensive, reliable, RFr $=1$, fist fist-sized cryocoolers. The central challenge has been development of sufficiently sensitive, reliable HTS sensors with adequate magnetic background noise rejection.

\section{Methods}

In the medical environment, the background fields may be orders of magnitude greater than the biomagnetic signal. Acrucial technique for suppressing background noise is magnetic gradiometry, the measurement of differences in magnetic field between two or more points in space. These spatial difference measurements reject the spatially uniform fields from distant noise sources, but detect the nonuniform fields from nearby signal sources.

Magnetic gradient measurements are difficult to make using HTS SQUIDs. Low-Temperature Superconductor (LTS) sensors, superconducting pickup coils are balanced so the net response to a spatially uniform field is nearly zero, allowing sufficient SQUID sensitivity to detect small biomagnetic signals. Unfortunately, such gradient pickup coils are difficult to fabricate in HTS $[3,4]$. The straightforward alternative of subtracting the outputs of separate SQUIDs, requires tremendous linearity and dynamic range because each SQUID must independently track the ambient noise as well as the small biomagnetic signal.

Our approach employs the TSG, developed at IBM, which requires neither gradient coils nor exceptional dynamic range. To eliminate the need for gradient pickup coils, the magnetic gradient is determined by subtracting the outputs of two SQUIDs. To minimize requirements for dynamic range, an additional SQUID monitors the magnetic background, and a feedback system is used to subtract most of the background field from the inputs to the two 


\section{DISCLAIMER}

Portions of this document may be illegible in electronic image products. Images are produced from the best available original document. 
gradient-sensing SQUIDs. This system removes the key obstacles to the use of HTS SQUIDs in magnetically unshielded environments.

With this practical HTS SQUID technology, we can develop a simple, mobile biomagnetic measurement system suitable for rapid, contactless assessment of vital electric functions. This system could be portable, compact, even hand-held, because small, efficient closed-cycle refrigerators are available for cooling to liquid-nitrogen temperatures. For maximum background rejection, the instrument is a second-order magnetic gradiometer, with three HTS SQUIDs performing second-order magnetic difference measurement, and two additional sensors measuring the amplitude and first-order gradient of the magnetic background field. The sensor array is mounted in a small vacuum-insulated dewar which can be placed on the patient's thorax. The dewar is designed so that the TSG can be oriented to measure magnetic fields parallel to, or perpendicular, to the surface of the patient's body. The sensors are cooled by heat conduction to a small refrigerator mounted a few inches away. The optimal distance from refrigerator to sensor array remains to be determined. Engineering design options include "transferring the cold" through a long copper braid or recirculating helium gas in order to move the refrigerator farther from the object of interest.

\section{Discussion}

Eventually, HTS TSGs may have a substantial impact in this area due to the reduced cost of cryogenic support for these systems. Initially, however, their impact may be in scanning capabilities, i.e., rapid qualitative assessment of

tissue "status" and localization of anomalies, which may be achieved in a contactless, nonintrusive fashion. The portability of HTS instruments will be crucial in this area. In addition, the development costs will be relatively low since the biomagnetic signals will be within the sensitivity of existing HTS SQUIDs.

It is envisioned that such systems have potential for application in medical scenarios which require rapid initial patient assessment, stabilization, and transport, i.e., emergency medicine/trauma management applications and remote or hostile (battlefield) environments. Management of high risk pregnancy and the premature infant are also promising areas for such technology $[5,6]$.

Other potential applications of cardiobiomagnetometers include critical situation monitoring of human physiologic "readiness." Representative scenarios include pre-flight assessment of fighter pilots performing high-g maneuvers and on-call assessment of surgeons prior to the procedure.

\section{Summary}

HTS SQUID technology provides the opportunity for development of simple, mobile biomagnetic measuring systems suitable for rapid, contactless assessment of vital bioelectric functions. By employing an intelligent, useroriented approach to engineering design considerations, a true service may be provided to the biomedical community in early patient intervention and management strategies.

\section{References}

[1] Achenbach S, Moshage W, Gohl K, Abraham-Fuchs, Schneider S, and Bachmann $\mathrm{K}$ (1992) In: Hoke M, Erne SN, Okada YC, and Romani GL (eds) Biomagnetism: Clinical Aspects, Excerpta Medica, New York, pp 453457.

[2] Fenici RR, Melillo G, Cappelli A et al. (1989) Advances in Biomagnetism, Plenum Press, New York, pp 441-444.

[3] Ferrari MJ, et al., Appl. Phys. Lett. 60, 1516 (1992).

[4] Keene MN, et al., "Thin Film HTc SQUID Construction and Characterization," Applied Superconductivity Conference, August, 1992.

[5] Kariniemi V, Ahopelto J, Karp PJ, and Katila TE, J. Perinat. Med. 2, 214 (1974).

[6] Awano I, Muramoto A, and Awano I, Tohoku J. Exp. Med. 138, 367 (1982). 


\section{DISCLAIMER}

This report was prepared as an account of work sponsored by an agency of the United States Government. Neither the United States Government nor any agency thereof, nor any of their employees, makes any warranty, express or implied, or assumes any legal liability or responsibility for the accuracy, completeness, or usefulness of any information, apparatus, product, or process disclosed, or represents that its use would not infringe privately owned rights. Reference herein to any specific commercial product, process, or service by trade name, trademark, manufacturer, or otherwise does not necessarily constitute or imply its endorsement, recommendation, or favoring by the United States Government or any agency thereof. The views and opinions of authors expressed herein do not necessarily state or reflect those of the United States Government or any agency thereof. 